\title{
Frenectomia com indicação ortodôntica para fechamento de diastema interincisal superior: um relato de caso
}

\author{
Frenctomy with orthodontic indication for closure of the upper interincisal diastema: \\ a case report
}
Frenctomía con indicación ortodóncica para cierre del diastema interincisal superior: reporte de un caso

Lucas Menezes dos Anjos ${ }^{1 *}$, Aurélio de Oliveira Rocha ${ }^{2}$, Rafaela de Menezes dos Anjos Santos ${ }^{1}$, Nailson Silva Meneses Júnior ${ }^{1}$, Marcos Antônio Lima dos Santos ${ }^{1}$, Itana Silva Santos ${ }^{1}$, Thaine Oliveira Lima ${ }^{2}$, Rayle Monteiro Andrade ${ }^{1}$, Maraiza Alves de Oliveira1', Sílvia Regina Santos Menezes¹.

\section{RESUMO}

Objetivo: Descrever um caso de diastema interincisal superior, em que foi realizada frenectomia para remoção de freio labial e tecido hipertrófico interincisal para posterior tracionamento ortodôntico e restabelecimento da harmonia do sorriso e oclusão. Detalhamento do caso: Paciente 24 anos, gênero masculino, encaminhado pelo ortodontista para avaliação e conduta de frenectomia labial superior. O paciente relatou que fez uso de chupeta até os seis anos de idade e que apresentava dificuldade na higienização dos incisivos centrais superiores, assim como limitação na movimentação do lábio superior e insatisfação com a estética do seu sorriso, principalmente pela presença do diastema entre os incisivos superiores. Ao exame clínico foi constatada inserção baixa do freio labial superior e presença de tecido fibroso interincisal estendendo-se da região interpapilar vestibular à região anterior do palato. A proposta de tratamento para o caso foi a realização de frenectomia labial superior, permitindo então posterior reposicionamento labial superior e remoção completa de tecido hipertrófico interincisal. Considerações finais: A remoção do freio labial superior, seguida de posicionamento dos dentes por meio de tratamento ortodôntico, é uma conduta simples, de fácil execução e com resultados previsíveis e consagrados pela literatura.

Palavras-chave: Freio labial, Ortodontia, Diastema.

\begin{abstract}
Objective: Describe a case of superior interincisal diastema which frenectomy was performed to remove the lip frenulum and the intertrophic hypertrophic tissue for subsequent orthodontic traction and restoration of smile harmony and occlusion. Case details: A 24-year-old male patient was referred by the orthodontist for evaluation and management of upper lip frenectomy. The patient reported that he used a pacifier until the age of six years, and he had difficulty in cleaning the upper central incisors, as well as limitation in the movement of the upper lip and dissatisfaction with the aesthetics of his smile, mainly due to the presence of the diastema between the incisors superiors. Clinical examination revealed a low insertion of the upper labial frenum and the presence of fibrous interincisal tissue extending from the vestibular interpapillary region to the anterior region of the palate. The proposal treatment for this case was perform an upper lip frenectomy, then allowing for posterior upper lip repositioning and complete removal of hypertrophic interincisal tissues. Final considerations: The removal of the upper lip frenulum followed by the traction of the teeth by means of orthodontic treatment is a simple procedure, easy to perform and with predictable results proven in the literature.
\end{abstract}

Keywords: Lip frenulum, Orthodontics, Diastema.

${ }^{1}$ Universidade Federal de Sergipe (UFS), Aracaju - SE. *E-mail: luks_anjos@hotmail.com

2 Universidade Tiradentes (UNIT), Aracaju - SE.

SUBMETIDO EM: 6/2021

ACEITO EM: 6/2021

PUBLICADO EM: 6/2021 


\section{RESUMEN}

Objetivo: Describir un caso de diastema interincisal superior en el que se realizó una frenectomía para extirpar el labio y el tejido hipertrófico intertrófico para posterior tracción ortodóncica y restauración de la armonía y oclusión de la sonrisa. Detalles del caso: Un ortodoncista derivó a un paciente de 24 años para la evaluación y el tratamiento de una frenectomía del labrum superior. El paciente refirió que utilizó chupete hasta los seis años, y que tenía dificultad para limpiar los incisivos centrales superiores, así como escaso movimiento del labio superior e insatisfacción con la estética de su sonrisa, principalmente por la presencia del diastema entre los incisivos. El examen clínico reveló una inserción baja del frenillo labial superior y la presencia de tejido fibroso interincisal que se extendía desde la región interpapilar bucal hasta la región anterior del paladar. La propuesta de tratamiento para el caso fue realizar una frenectomía del labio superior, que luego permitió el reposicionamiento del labio superior posterior y la remoción completa de los tejidos interincisales hipertróficos. Consideraciones finales: La remoción del freno del labio superior seguida del posicionamiento de los dientes mediante tratamiento de ortodoncia es un procedimiento sencillo, fácil de realizar y con resultados predecibles y consagrados en la literatura.

Palabras clave: Freno labial, Ortodoncia, Diastema.

\section{INTRODUÇÃO}

A utilização de aparelho ortodôntico para alinhamento dentário é um tratamento consagrado na literatura e com alto índice de aceitação pelos pacientes (MOTTA AFJ, et al., 2012). A busca por um sorriso harmônico e esteticamente perfeito está associada à autoaceitação individual, à elevação da autoestima e ao bem-estar, influenciando também nas relações sociais (SILVA PQ, et al., 2020).

Um impasse para o alinhamento dentário satisfatório é a presença de um freio labial superior hipertrófico, o qual é caracterizado por uma prega sagital de mucosa alveolar e de tecido fibroso. Apresenta aspecto triangular, sendo inserido na linha mediana da superfície interna do lábio superior, estendendo-se à gengiva inserida entre os incisivos centrais superiores (ZIMERMANN CO, et al., 2017). Portando, em situações em que o freio labial hipertrófico apresenta uma inserção transpapilar ou seja, localizado na face vestibular ao redor da linha mediana entre incisivos, ligando à palatina do arco superior, pode levar à corrência de diastema interincisal (PLACEK M, et al., 1974).

Os diastemas, ou espaços interdentais, podem ocorrer em qualquer região do arco dentário, geralmente se encontram entre os incisivos centrais superiores. Em crianças pré-escolares sua frequência é maior, principalmente na fase em que há presença de dentes decíduos e permanentes, denominada fase da dentição mista (DEAN JÁ, et al., 2011).

Quando os diastemas estão associados à posição anormal do freio labial superior, podem levar à dificuldade de higienização dos dentes, levar à formação de bolsas periodontais, assim como interferir de forma negativa na formação do paciente, comprometendo sua qualidade de vida (MCDONALD RE e AVERY DR, 1995; CAVALCANTE JA, et al., 2009). Pode ainda restringir os movimentos labiais e comprometer a estética, sendo indicado, nesses casos, uma medida terapêutica cirúrgica (ZIMERMANN CO, et al., 2017).

Quando a correção fisiológica do diastema não ocorre, estando associada à presença de um freio labial hipertrófico, há necessidade de intervenção cirúrgica, sendo os tratamentos indicados a frenectomia, que visa a remoção total das fibras hipertróficas, ou frenolotomia, procedimento que tem o intuito de remover parcialmente o tecido fibroso, estando o último associado a altas taxas de recidiva (PRATO GP, et al., 1995).

Quando bem indicado, o procedimento de frenectomia apresenta prognóstico favorável, além de ser considerado um procedimento cirúrgico simples, pouco traumático e com recuperação tranquila. A técnica cirúrgica consiste em excisão do tecido fibroso interincisal da região vestibular à inserção palatina, assim como reposicionamento do freio labial superior por meio de sua remoção e divulsionamento de suas fibras (MALENTACCHI A, et al., 2020). 
Diante disso, o objetivo do presente estudo é detalhar e discutir um caso clínico no qual foi realizado o procedimento cirúrgico de frenectomia com a finalidade de corrigir o diastema interincisal com indicação ortodôntica.

\section{DETALHAMENTO DO CASO}

Paciente 24 anos, gênero masculino, encaminhado pelo ortodontista para avaliação e conduta de frenectomia labial superior. O termo de consentimento livre esclarecido (TCLE) foi assinado pelo paciente, tendo o mesmo, ciência da utilização das suas imagens para fins acadêmicos. Uma anamnese detalhada foi realizada, onde não foram informadas quaisquer comorbidades sistêmicas, assim como reação alérgica a anestésicos locais ou medicações.

O paciente relatou que fez uso de chupeta até os seis anos de idade e que apresentava dificuldade na higienização dos incisivos centrais superiores, assim como limitação na movimentação do lábio superior. Relatou ainda insatisfação com a estética do seu sorriso, principalmente pela presença do diastema entre os incisivos superiores, situação que o fez procurar tratamento ortodôntico afim de fechar o espaço existente.

Ao exame clínico, foi constatada inserção baixa do freio labial superior, situação que dificultava a movimentação natural labial, assim como presença de tecido fibroso interincisal, estendendo-se da região interpapilar vestibular à região anterior do palato, mais precisamente próximo à papila nasopalatina (Figura 1). A extensão do freio, assim como do tecido fibroso, é evidenciada tracionando-se o lábio superior a fim de causar isquemia nos tecidos a serem manipulados, manobra que deve ser realizada tanto no diagnóstico como na execução da cirurgia.

Figura 1 - Diagnóstico da inserção baixa do freio labial superior.

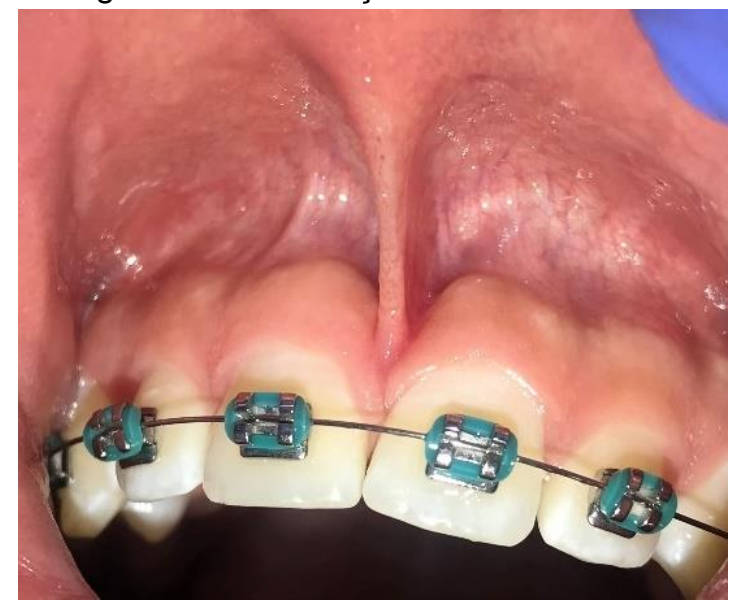

Fonte: Anjos LM, et al., 2021.

A proposta de tratamento para o caso foi a realização de frenectomia labial superior, permitindo então posterior reposicionamento labial superior e remoção completa de tecido hipertrófico interincisal, situação necessária para correto reposicionamento dentário pelo ortodontista.

Os protocolos de antissepsia foram devidamente seguidos utilizando clorexidina $2 \%$ da região extraoral e clorexidina $0,12 \%$ na região intraoral. O procedimento foi iniciado com anestesia tópica com Benzotop (200 $\mathrm{mg} / \mathrm{g}$ ), seguida de bloqueio alveolar superior anterior e nasopalatino com lidocaína $2 \%$ com epinefrina 1:100.000 (DFL®), assim como anestesia do tipo infiltrativa com a finalidade de diminuir o sangramento regional, conduta adotada para que se consiga um campo operatório com melhor visualização. As anestesias infiltrativas foram realizadas ao redor do freio labial, evitando anestesiar de forma direta em sua inserção, situação que poderia causar produção de edema local dificultando sua extensão, assim como a realização da incisão. 
Após se certificar da analgesia completa da região, o lábio superior foi tracionado para permitir visualização completa da área a ser operada. Uma pinça do tipo hemostática reta foi utilizada para apreender o freio labial superior, conduta adotada para delimitar a extensão de tecido que foi excisada (Figura 2). Uma lâmina de bisturi número $15 \mathrm{C}$ acoplada ao seu respectivo cabo foi usada para realização da incisão, a mesma foi feita seguindo o contorno da extremidade ativa da pinça hemostática, realizando inicialmente duas incisões, uma na região voltada para o lábio superior, seguida de uma segunda incisão na região da ponta ativa da pinça voltada para os dentes.

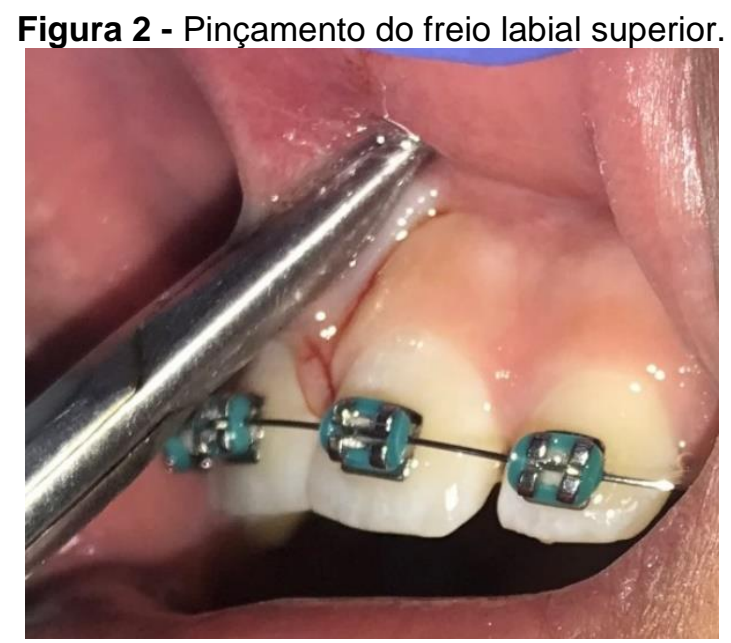

Fonte: Anjos LM, et al., 2021.

Depois da remoção completa do tecido pinçado - correspondente ao freio labial superior -, foi feita a excisão do tecido hipertrófico interincisal (Figura 3). Para tal, a incisão deve ir da região vestibular entre os incisivos centrais superiores à região do palato, próximo a papila nasopalatina.

O tecido hipertrófico foi então removido. Para certificar-se da remoção completa de todo tecido fibroso, uma gaze estéril embebida em soro fisiológico foi utilizada para remoção de possíveis restos de tecido, que posteriormente poderiam causar recidiva. Para tal, a gaze foi friccionada com leve pressão entre os incisivos centrais.

Figura 3 - Remoção do freio labial superior e tecido hipertrófico interincisal.

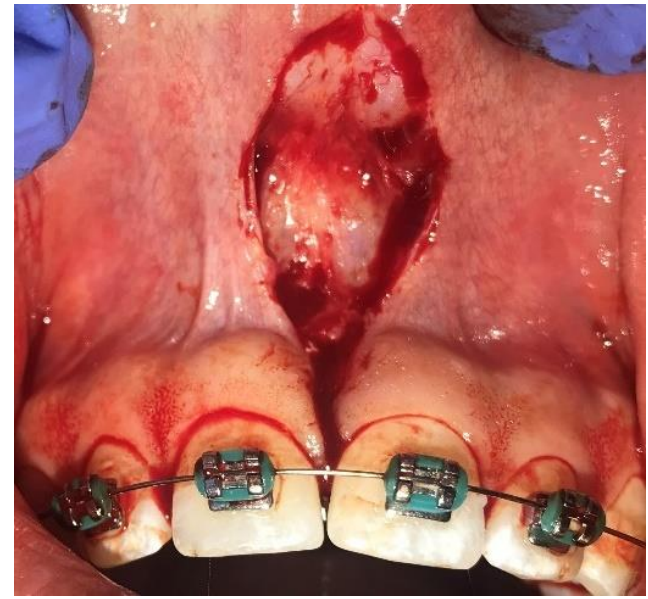

Fonte: Anjos LM, et al., 2021.

A pinça hemostática foi então usada para divulsionar a região excisada do freio labial superior, permitindo, assim, que suas fibras sejam rompidas e o lábio fique mais solto e móvel (Figura 4). 
Figura 4 - Divulsionamento da região excisada.

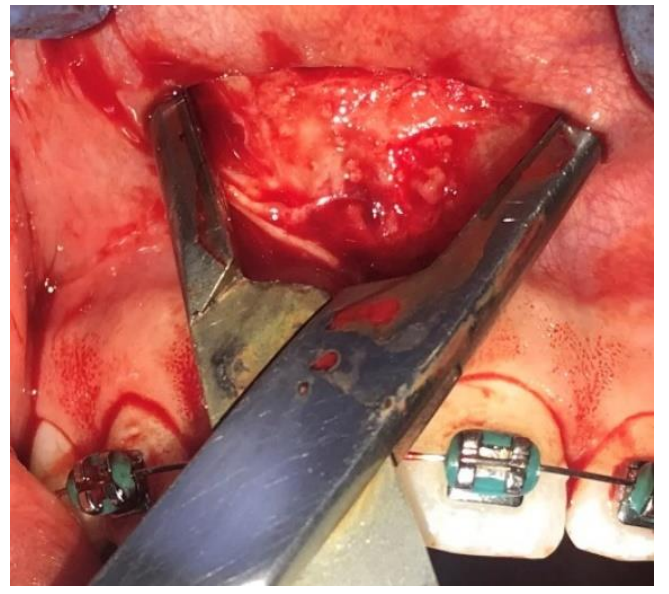

Fonte: Anjos LM, et al., 2021.

Seguiu-se com irrigação copiosa da região com soro fisiológico estéril e sutura por meio de pontos simples com fio nylon 3-0 (SHALON®) (Figura 5 e 6). Para controle da dor e inflamação pós-operatória foi prescrito Nimesulida (100mg) de 12/12 horas por três dias, Dipirona $(500 \mathrm{mg}$ ) de 04/04 horas por três dias e Clorexidina $(0,12 \%)$, sendo solicitado bochecho $12 / 12$ horas dois dias após do procedimento cirúrgico. Foi solicitado à paciente retorno com sete dias para remoção dos pontos cirúrgicos e avaliação pós-operatória. Após o período de 15 dias, o paciente estava liberado para prosseguir com o tratamento ortodôntico.

Figura 5- Pós-operatório imediato com ferida cirúrgica após sutura.

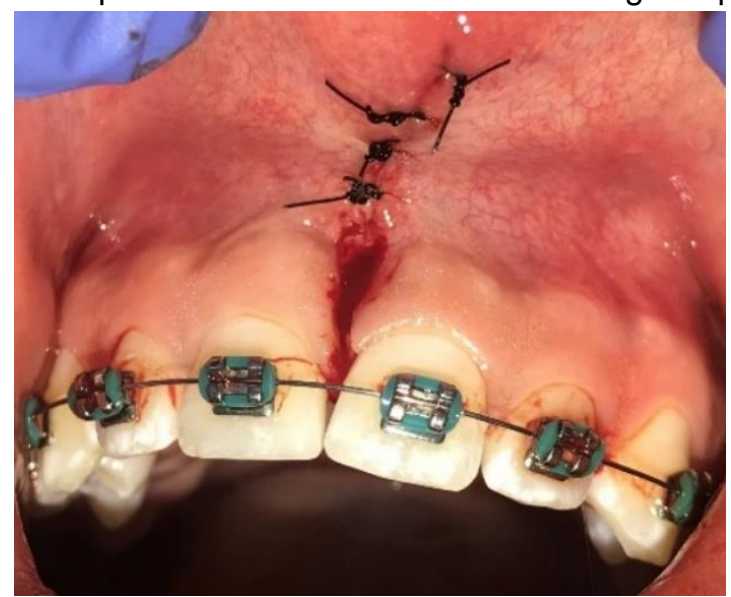

Fonte: Anjos LM, et al., 2021.

Figura 6 - Pós-operatório imediato da região palatina.

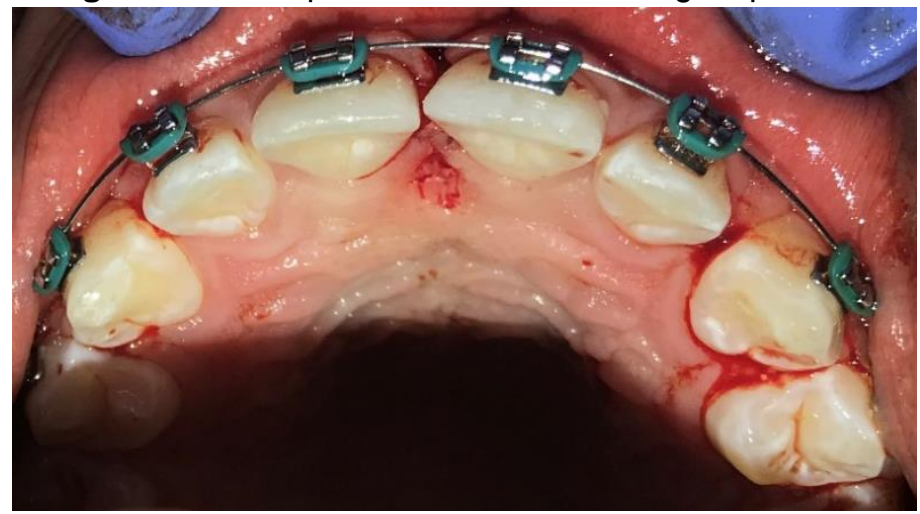

Fonte: Anjos LM, et al., 2021. 


\section{DISCUSSÃO}

A presença de espaço entre duas unidades dentárias é denominada diastema, sendo essa uma das principais queixas de pacientes que procuram tratamento ortodôntico, pois alegam comprometimento estético interferindo na harmonia do sorriso (CAL NETO JOAP, et al., 2010; COTA ALS, et al., 2019). Entre os 8 e 10 anos de idade, período em que a criança está na fase da dentição mista, ou seja, há presença de unidades dentárias decíduas e permanentes, é comum a presença de diastemas logo após a troca dos incisivos centrais e laterais, tanto da arcada superior quanto da inferior (ZIMERMANN CO, et al., 2017).

Com o desenvolvimento normal do sistema estomatognático e a erupção dos caninos permanentes, ocorre a redução espontânea dos diastemas (COTA ALS, et al., 2019). Contudo, a literatura mostra que diastemas maiores que $1,85 \mathrm{~mm}$, mesmo na fase da dentição mista, apresentam cerca de $50 \%$ de chance de regredirem (COTA ALS, et al., 2019). No caso clínico em questão, o paciente procurou tratamento ortodôntico aos 24 anos e não foi notada regressão do diastema.

Vários são os fatores etiológicos que podem levar a diastemas interincisivos na dentição mista ou permanente, sendo os mais comuns a ausência congênita ou tamanho reduzido dos incisivos laterais, perímetro do arco maior do que o diâmetro dos dentes permanentes, hereditariedade, sucção do polegar ou chupetas de borracha, macroglossia e dentes supranumerários (FONSECA TMC, et al., 2017). No caso clínico em questão, o paciente dispunha de dentição permanente, ao realizar anamnese, o mesmo relatou que fez uso de chupeta até os seis anos de idade.

Em situações que há presença de freio labial curto ou tetolabial e/ou diastemas interincisvos que não regridem de forma fisiológica após a erupção dos caninos gerando limitação functional ou estética, o tratamento cirúrgico é a terapia indicada (DA SILVA CAVALCANTE SK, et al, 2021).

A literatura é controversa quanto ao momento a ser realizada a frenectomia, se antes da instalação do aparelho ortodôntico ou depois. Mas, os dados literários mostram que a monobra cirúrgica só deve ser feita após a erupção completa dos incisivos centrais permanentes, assim como dos caninos permanentes, para que se possa excluir a possibilidade de fechamento fisiológico do diastema (GOMES JDL, et al, 2021; FONSECA TMC, et al., 2017). No caso relatado, por se tratar de um paciente de 24 anos, o mesmo não apresentava dentição decidua e a conduta de realização do procedimento cirúrgico foi adotada após a instalação do aparelho ortodôntico.

A intervenção cirúrgica para os casos de freio labial curto pode ser do tipo frenolotomia ou frenectomia. A frenolotomia consiste na remoção parcial do freio labial. Já a frenectomia consiste na excisão cirúrgica com a finalidade de corrigir ou eliminar anomalias anatômicas da gengiva e/ou da mucosa alveolar, conduta que apresenta baixas taxas de recidiva quando comparada com a frenolotomia (VALLADARES NETO J, et al., 1996; ROSA PMM, et al., 2018).

No caso clínico, relatado o paciente apresentava freio labial curto, o que dificultava a plena movimentação do lábio superior, assim como tecido hipertrófico entre os incisivos centrais superiores, levando à presença de diastema. Devido à baixa taxa de sucesso de fechamento do diastema por meio de tracionamento ortodôntico, assim como o alto risco de recorrência, segundo as recomendações indicadas pela literatura, foi proposto excisão cirúrgica desses tecidos por meio da técnica de frenectomia labial superior.

A identificação correta do freio labial, assim como sua real extensão, é de fundamental importância para o correto diagnóstico e tratamento. A identificação de sua extensão pode ser feita realizando certa pressão de tração no lábio, isso levará ao surgimento de uma espessa faixa de tecido isquêmico caracterizada por uma base larga em forma de leque que estará inserida na papila palatina (MACEDO MP, et al., 2012; ROSA PMM, et al., 2018).

Segundo Dos Santos Silva CL, et al. (2020), a técnica anestésica deve ser realizada por meio de bloqueio alveolar seguindo o longo eixo do dente, e as injeções infiltrativas devem ser feitas ao redor do freio labial, evitando anestesiar de forma direta em sua inserção, situação que poderia causar produção de edema local, dificultando sua extensão, assim como a realização da incisão. Tais indicações foram seguidas no caso relatado. 
A realização da frenectomia com o uso de bisturi manual é ainda a mais executada e com maiores índices de descrição na literatura (DELLI K, et al., 2015). Uma outra forma de realizar a frenectomia é com a utilização de laser de alta potência. Segundo Júnior RM, et al. (2015), o laser de alta potência reduz o tempo cirúrgico por promover isquemia e cauterização à medida que realiza a incisão do tecido. $O$ autor relata ainda que, como regra geral, não há necessidade de realização de sutura, fato que reduz os índices de edema e possível trauma dos tecidos moles associados a sutura no pós-operatório. O custo elevado dos equipamentos de laser, assim como capacitação específica para seu manuseio, mostrado-se como principais desvantagens dessa técnica (JUNIOR RM, et al., 2015).

Contudo, não há indícios na literatura de diferença estatisticamente significante associado a taxas de sucesso entre a técnica realizada com bisturi convencional ou por meio do laser de alta potência (DELLI K, et al., 2015; SILVA PQ, et al., 2020). No caso em questão, a incisão foi feita com um bisturi convencional, sendo realizada sutura, como preconizado pela literatura.

A presença de diastema entre os incisivos centrais superiores está corriqueiramente associada à baixa autoestima dos pacientes, situação que causa problemas sociais e comportamentais, interferindo de forma direta na qualidade de vida de escolares e adultos. A remoção do freio labial superior, seguida de posicionamento harmônico dos dentes por meio de tratamento ortodôntico, é uma conduta simples, de fácil execução e com resultados previsíveis e consagrados pela literatura. O correto diagnóstico e plano de tratamento traçado pelo ortodontista e cirurgião, assim como a execução de uma técnica cirúrgica minuciosa são fatores essenciais para resultados previsíveis e satisfatórios.

\section{REFERÊNCIAS}

1. ALMEIDA RR, Garib DG, et al. Diastema Interincisivos Centrais Superiores: quando e como intervir? R Dental Press Ortodon Ortop Facial, 2004; 9(2): 137-56.

2. CAL NETO JOAP, et al. Diastemas interincisais superiores associados a dentes supranumerários-considerações clínicas e relato de um caso. Jornal Brasileiro de ORTODONTIA \& Ortopedia Facial, 2010; 7(39).

3. CAVALCANTE JA, et al. Diagnóstico e tratamento cirúrgico do freio teto labial persistente em pacientes no período intertransitório da dentição mista - relato de caso. Rev Inst Ciênc Saúde, 2009; 27(3): 290-4.

4. COTA ALS, et al. Frenectomia para restituição fono-motricial da língua. Revista Eletrônica Acervo Saúde, 2019; (35): 1457-1457.

5. DA SILVA CAVALCANTE SK, et al. O uso do ácido hialurônico associado ao fechamento de diastema para tratamento de black spaces: estudo de caso clínico. Revista Eletrônica Acervo Saúde, 2021; 13(4): 6958-6958.

6. DOS SANTOS SILVA CL, et al. Frenectomia labial superior com laser cirúrgico de diodo: relato de caso clínico em paciente infantil. Research, Society and Development, 2020; 9(11): 91691110684-91691110684.

7. DEAN JÁ, et al. Odontopediatria: para crianças e adolescentes. Elsevier, 2011; 9.

8. DELLI K, et al. Facts and myths regarding the maxillary midline frenum and its treatment: a systematic review of the literature. Quintessence Int, 2013; 44(2): 177-87.

9. FONSECA TMC, et al. Frenectomia associada à ortodontia para fechamento de diastema. Revista Uningá, 2017; 29(1): 93-8.

10. GOMES JDL, et al. Anatomia, diagnóstico e tratamento de anquiloglossia na primeira infância. Revista Eletrônica Acervo Saúde, 2021; 13(2): 5815-5815.

11. HASS E. A relação entre frenectomia e Diastemas. Caderno de Odontologia, Universidade do Paraná, 2010.

12. JÚNIOR RM, et alLabial frenectomy with Nd:YAG laser and conventional surgery: a comparative study. Lasers Med Sci, 2015; 30(2): 851-6.

13. MALENTACCHI A, et al. Redução de diastema após exodontia de dente supranumerário e frenectomia-um relato de caso. Odonto, 2020; 28(55): 1-10.

14. MCDONALD RE, AVERY DR. Odontopediatria. Artes Médicas, 1995.

15. MOTTA AFJ, et al. A influência de determinadas características dentárias na avaliação estética do sorriso. Dental Press J Orthod, 2012; 17(3): 1-7.

16. PLACEK M, et al. Problems with the lip frenulum in periodontics. I. Classification and epidemiology of tendons of the lip frenulum. CeskStomatol, 1974; 74(5): 385-91.

17. PRATO GP, et al. Periodontol plastic and mucogingival surgery. Periodontol 2000, 1995; 9: 90-105.

18. ROSA PMM, et al. Diagnóstico e tratamento cirúrgico do freio labial com inserção marginal: relato de caso. Braz $\mathrm{J}$ Periodontol 2018; 28(1):56-60.

19. SILVA QP, et al. Correção de sorriso gengival associada à frenotomia labial superior em paciente com Erupção Passiva Alterada (EPA): um relato de caso. Revista Eletrônica Acervo Saúde, 2020; 12(12): 4156-4156.

20. VALLADARES NETO J, et al. O dilema do diastema mediano e o freio labial superior: análise de pontos fundamentais. Robrac. 1996; 6(19): 9-17.

21. ZIMERMAN CO, et al. Frenectomia Labial Em Paciente Infantil: Relato De Duas Técnicas Cirúrgicas. Revista Uningá Review, 2017; 29(2). 